\title{
Additive composition by normal and retarded children of matched MA'
}

DONALD L. MCMANIS, BUREAU OF CHILD RESEARCH, UNIVERSITY OF KANSAS, AND PARSONS STATE HOSPITAL AND TRAINING CENTER, Parsons, Kan. 67357

Normals and retardates from 5-10 in MA (with $1 Q$ controlled across $M A$ levels in each group) were tested for additive composition of classes using different colored wooden beads. Additive composition was positively related to $M A$ level within both IQ groups. Age placement for additive composition was MA 9 for normals, rather than $7-8$ as found by Piaget. Age placement of $M A \&$ for retardates, however, corresponded to Piaget's results. No transitional stage between additive and nonadditive composition of classes, reported by Piaget, was found in the present study.

Piaget (1952) found three age-related stages in development of the ability to additively compose classes. At the first stage (usually ages 5-6) children had a general impression of a total class and demonstrated that they knew wooden beads could be of different colors. However, when forced to break down this impression and compare part against whole (brown beads vs wooden beads) they behaved as if the whole class was destroyed and compared one partial class (brown beads) with the other partial class (white beads). Children at the second stage (also usually ages 5-6) had a more differential conception of a general class and its subclasses. When they were asked to compare part with whole, the whole was not destroyed, but identified with the part. They said that the brown beads and the wooden beads were the same in number. Third-stage children (usually ages 7-8) had an abstract conception of classes and said immediately that the wooden beads were more than the brown beads because there were white beads as well.

Elkind (1961) replicated Piaget's study, except that instead of having his Ss compare different colored wooden beads he had them compare the number of boys or girls against the total number of children in their classrooms. Elkind tested the relationship between the percentage of $S$ s at the three stages of additive thinking and $\mathrm{CA}$. He found that the stages were significantly related to age $(\mathrm{p}<.05)$ in agreement with Piaget's findings. Surprisingly, however, he found only a small percentage of children at the second, or transitional, stage.

The present study compared the MA levels at which additive composition occurred in elementary school children and in institutional retardates. IQ was matched across MA levels within each $S$ group to eliminate IQ effects except between the normal and retarded groups.

Subjects. Normal Ss were 90 elementary school children of average intelligence (IQ 85-115) on the Lorge-Thorndike test. They ranged from 5-3 to 10-10 in CA, and from 5-3 to 11-11 in MA. Retarded Ss were 90 children in a state institution. They ranged from 47 to 73 in IQ (1960 L-M Stanford Binet), from 7-8 to 21-2 in CA, and from 5-0 to 11-9 in MA. There were 15 Ss at each of six MA levels (5 to 10-11) in both IQ groups. MA groups were matched between normals and retardates, and IQ was matched across MA levels with in each $\mathrm{S}$ group.

Materials and Procedure. The materials consisted of 22 round wooden beads, 20 of which were colored yellow and two of which were colored red.

The Ss were seen individually and asked the following questions: (a) How many wooden beads are in the box? (b) How many yellow beads are in the box? (c) How many red beads are in the box? (d) Are there more wooden beads or more yellow beads in the box?

Questions $\mathrm{a}, \mathrm{b}$, and $\mathrm{c}$ were asked only to orient the children to the problem and to help them differentiate between the classes. The responses to Question d were categorized according to Piaget's three stages of additive composition.

Results. All responses indicating that the partial class was
Table 1

Per Cent of Ss at Each State of Additive Composition

\begin{tabular}{cccccccc} 
& \multicolumn{3}{c}{ Normal } & & \multicolumn{3}{c}{ Retarded } \\
\cline { 2 - 4 } \cline { 6 - 8 } MA & Stage 1 & Stage 2 & Stage 3 & & Stage 1 & Stage 2 & Stage 3 \\
\hline 5 & 80 & - & 20 & & 73 & - & 27 \\
6 & 73 & - & 27 & & 67 & - & 33 \\
7 & 87 & - & 13 & & 33 & - & 67 \\
8 & 53 & - & 47 & & 20 & - & 80 \\
9 & 27 & - & 73 & & 7 & - & 93 \\
$10-11$ & 20 & - & 80 & & 13 & - & 87 \\
\hline
\end{tabular}

greater than the total class (more yellow beads than wooden beads) were classed as Stage 1 responses. Responses indicating that the partial class was identical with the total class (yellow beads the same as the wooden beads) were classed as Stage 2 responses. Those responses stating that there were more wooden beads than yellow beads were classed as Stage 3 responses. There were no responses made by $\mathrm{Ss}$ in either IQ group stating the equality of the yellow and wooden beads. Thus, there were no Stage 2 responses obtained in the present study. The distribution of responses among the three stages for the 15 normal and 15 retarded Ss at each MA level is presented in Table 1.

It can be seen in Table 1 that the proportion of Stage 3 responses is positively related to MA level in both IQ groups, and that the proportion was greater at every MA level in the retarded group. The deviations of the obtained distributions for each group from a chance distribution $(50 \%$ Stage 1 and 50\% Stage 3 responses at each MA level) were tested by chi-square for each IQ group. For the normal Ss, the chi-square was 12.67 , significant at beyond the .05 level of confidence with five degrees of freedom. For the retardates, the chi-square was 15.67 , significant at beyond the .01 level of confidence with five degrees of freedom. Thus, the level of response was found to be significantly related to MA level with both IQ groups. Since the proportion of Stage 3 responses in the retarded group exceeded that in the normal group at every MA level, a chi-square test was also conducted to test for significance in the differences of the two distributions. Using the obtained marginal totals to calculate the expected frequencies within each cell, a chi-square of $3.99(p>.50$, df $=5$ ) was obtained. This indicated that the difference in distribution of Stage 3 responses in the two IQ groups was not significantly greater than chance.

Discussion. The present results confirmed Piaget's finding that ability to additively compose classes is related to level of mental development. However, the age placement of the third stage of additive composition for the present sample of normal Ss was later (MA 9) than Piaget's findings would have suggested. The age placement of the third stage for the retarded Ss (MA 8) corresponded to Piaget's findings. The complete absence of Stage 2 responses in the present study failed to confirm Piaget's analysis of additive composition as developing in three clearcut stages. The present results suggest that while the emergence of additive composition was gradual in terms of the proportion of Ss at each MA level displaying it, for individual Ss it was an all-or-none phenomenon.

\section{REFERENCES}

ELKIND, D. The development of the additive composition of classes in the child: Piaget replication study III. J. genet. Psychol., 1961, 99, 51-57.

PIAGET, J. The child's conception of number. London: Kegan Paul, 1952. NOTE

1. This study done under the support of NICHHD Grant No. 00870, Bureau of Child Research, University of Kansas. 